\title{
PROPOSTA DE METODOLOGIA DE DEFINIÇÃO DE CARTA GEOTÉCNICA BÁSICA EM REGIÕES TROPICAIS E SUBTROPICAIS
}

\author{
Regina Davison DIAS
}

\begin{abstract}
RESUMO
O trabalho apresenta a metodologia de definição de carta geotécnica básica que está sendo usada no Sul do Brasil. A unidade geotécnica é estimada considerando a superposição da pedologia e a geologia. Em zonas urbanas, é feito um estudo pedológico simplificado voltado para a geotecnia. Estimadas as unidades e os horizontes de solos, são realizados trabalhos de campo com vistas a análises morfológicas e retiradas de amostras para ensaios de laboratório. Os ensaios geotécnicos são simples, mas apropriados para as aplicações. Uma descrição dos perfis típicos existentes na unidade e seu comportamento acompanha o mapa geotécnico. Desta maneira, o profissional de planejamento, ou outro usuário, pode ter uma estimativa do tipo de material a ser encontrado na unidade. O conhecimento do meio físico, comportamento geomecânico e hidráulico visam às aplicações onde o solo é solicitado, como nos casos de fundações, escorregamentos de encostas, jazidas de solos destinados à pavimentação, habitações de baixo custo, pequenos açudes e barragens. Estima também locais ou horizontes suscetíveis à erosão e com drenagens apropriadas para aterros de rejeitos.
\end{abstract}

\section{ABSTRACT}

This paper presents the methodology for the definition of geotechnical maps that is being used in Southern Brazil. The unit is defined considering the superposition of pedology and geology. In urban regions, a simplified pedological study is performed with geotechnical applications in mind. Once geotechnical units are defined, together with soils layers, field work is performed, involving morphological analysis and soil sampling for laboratory testing. Simple soil tests are performed in the laboratory, appropriate to the required applications. A description of possible typical soil profiles is included in the geotechnical map. In this way, urban planners, or other professionals, can estimate the type of material to be founded in the geotechnical unit. A knowledge of physical environment, geomechanical and hydraulic behavior, helps the analysis of applications where the soil is loaded by foundations, landslides, borrow pits for pavements, low cost housing, and small dams. This methodology helps to estimate soil layers susceptible to erosion, as well as layers with drainage characteristics adequate for landfills.

\section{INTRODUÇÃO}

O uso e ocupação do solo em zonas urbanas é um fato preocupante no Brasil. Existem cada vez mais áreas críticas, devendo o processo de expansão ser otimizado para diminuir os riscos de problemas. Estes casos mostram a necessidade de um conhecimento das características dos terrenos frente a esta ocupação acelerada. A cartografia geotécnica define métodos nos quais procura enquadrar unidades territoriais homogêneas formulando orientações técnicas para a ocupação destas unidades. Para a definição de unidades homogêneas, é necessário o conhecimento geotéc- nico do subsolo brasileiro com seus múltiplos universos.

Os mapeamentos geotécnicos, em geral, não apresentam propriedades de comportamento dos solos. Esta tradição foi importada da Europa ou Estados Unidos, de países cujo comportamento geotécnico já está bem posicionado. Nestes, estudos qualitativos, a partir de sistemas de classificação, baseados em índices de plasticidade e análise granulométrica, podem fornecer estimativas genéricas de comportamento destes solos. Tais sistemas de classificação tradicionais são específicos para um estudo pontual de ocorrência e profundidade, não considerando os horizontes com suas gêneses 
específicas. Numa mesma classe, podem ser enquadrados solos com diferentes comportamentos às várias aplicações. Um solo argiloso, tratado nas referências clássicas de mecânica dos solos, é considerado de baixa permeabilidade, com comportamento diferenciado, a curto e a longo prazo, de resistência e compressibilidade. Já, no Brasil, pode ser encontrado este tipo de argila, mas também as lateríticas, porosas e bem drenadas, as expansivas, as pré-adensadas por cimentação química, entre outras. Estes solos fazem parte de diferentes universos geotécnicos.

O Brasil apresenta mais de $80 \%$ do seu território coberto por solos tropicais e subtropicais com comportamento particular diferindo, em muitos aspectos, dos tradicionais solos estudados nas Referências Bibliográficas. Vários tipos de rochas são encontrados no Brasil. Através da ação dos processos geológicos e pedogenéticos, são formados os perfis de solos.

Considerando os vários estudos já realizados por DIAS (1987, 1988, entre outros), sobre solos tropicais e subtropicais brasileiros e em orientação de várias dissertações de mestrado como as de GONZALES (1981), MAGALHÃES (1990), SANTOS (1990), BASTOS (1991), PINHEIRO (1991), ORLANDINI (1991), abrangendo solos do Rio Grande do Sul, Santa Catarina, Paraná, Bahia e Amazonas - foi possível definir uma metodologia de enquadramento de unidades geotécnicas e estudo de novas áreas. Maiores detalhes da metodologia foram divulgados por DIAS \& MILITITSKY (1990). Esta metodologia já foi testada com bons resultados para os seguintes locais: norte do Rio Grande do Sul (DIAS, 1988); município de Porto Alegre, em solos oriundos de rochas cristalinas (BASTOS, 1991); municípios de Novo Hamburgo e Campo Bom, em solos oriundos de arenito (ORLANDINI, 1991); região de solos residuais da Formação Rosário do Sul (PINHEIRO, 1991) e para solos da região metropolitana de Porto Alegre (DIAS et al., 1993, 1994). Estão em fase de publicação estudos junto à CPRM e METROPLAN. Atualmente a metodologia está sendo aplicada também nas Universidades Federais do Rio Grande, Santa Maria e Santa Catarina.

\section{ESTIMATIVAS DE UNIDADES GEOTÉCNICAS}

O estabelecimento de unidades geotécnicas tem por objetivo a definição de regiões cujo comportamento geotécnico frente ao uso e à ocupação do solo é semelhante. A estimativa de unidades geotécnicas consiste no emprego dos dados reunidos e interpretados em um trabalho cartográfico que visa delimitar as zonas de ocorrência de solos com perfis de origem e características físicas e morfológicas semelhantes. Estas constituem as chamadas unidades geotécnicas.

Para a estimativa das unidades geotécnicas, está sendo utilizada a técnica de superposição de cartas geológicas, pedológicas, topográficas, com o objetivo de originar uma nova carta. Para cada unidade geotécnica, a geologia permite inferir as características do horizonte de alteração da rocha (horizonte saprolítico) e a pedologia permite inferir características dos horizontes superficiais dos seus perfis típicos. A topografia auxilia na definição dos limites entre as unidades. A classificação de uma unidade geotécnica é estimada usando a seguinte simbologia:

\section{"ABCxyz"}

onde as letras maiúsculas " $\mathrm{ABC}$ " correspondem à classificação pedológica do horizonte superficial (horizontes A e B) e as minúsculas "xyz", identificadoras da geologia, caracterizando os horizontes C, RA e R. Estas podem ser constituídas de três ou menos letras. Usar o sistema de classificação pedológico corrente na prática brasileira para os horizontes superficiais A e B, conforme publicado por CAMARGO et al. (1987). Na classificação geológica, é considerada a rocha dominante. No caso de haver mais de uma litologia dominante no material do substrato, adotam-se as siglas destas litologias em letras minúsculas separadas por vírgulas. Nas classificações pedológicas são ignoradas as características húmico (h), álico (a), eutrófico (e) ou distrófico (d). A formação geológica ou grupo pode ser colocada entre parênteses em letras maiúsculas.

\section{ESTUDO PEDOLÓGICO SIMPLIFICADO DIRIGIDO PARA A GEOTECNIA}

Considerando as dificuldades de que os estudos não são desenvolvidos para as zonas urbanas, propõe-se um estudo pedológico simplificado voltado para a geotecnia. Esta simplificação deve-se ao fato de que o horizonte A, importante na agronomia, geralmente é desprezado nas aplicações geotécnicas. Desta forma, pode ser dada uma maior ênfase no horizonte C, que é bastante complexo e importante o seu conhecimento na geotecnia. 
O trabalho inicial consiste em analisar os levantamentos de solos, geológicos, topográficos, geomorfológicos, fotografias aéreas, imagens de satélites e todas as informações importantes da região. O mapa geomorfológico deve separar os relevos em plano, suavemente ondulado, ondulado e fortemente ondulado, segundo os critérios do Manual de metódos de trabalho de campo (LEMOS et al., 1982).

3.1 Estimativa preliminar de unidades geotécnicas

Usando o material produzido no item anterior, a carta geotécnica pode ser esboçada através dos seguintes procedimentos: a) Divide-se a região em grandes unidades. Quando existem mapas geológicos em maiores escalas dos locais a serem definidos pela cartografia, subdividem-se as grandes unidades de acordo com a geologia.

b) Usando-se os resultados dos levantamentos pedológicos, mesmo os de pequenas escalas, pode-se ter uma estimativa dos principais perfis de solos existentes na região.

c) Separam-se os solos hidromórficos dos não-hidromórficos. No Brasil, há uma grande ocorrência de solos não-hidromórficos. Isto é, quando o lençol freático não se encontra nos horizontes A e B.

d) Nas unidades situadas em relevo ondulado, separar os locais onde o relevo é fortemente ondulado, ondulado e suavemente ondulado. As variações do relevo e a geologia servem como indicadores das unidades geotécnicas.

e) Indicar, no mapa inicial, a presença de falhas e fissuras, além de outros aspectos importantes da estrutura definidos nos mapas geológicos. Estimar as características do horizonte $\mathrm{C}$ a partir da geologia (mineralogia) e experiência anteriores.

f) Inicialmente, os solos hidromórficos podem ficar num grande grupo. Posteriormente podem ser separados. Neste caso, separar as unidades situadas próximas aos rios ou lagoas daquelas que ocorrem entre elevações. Nas depressões, verificar os locais presentes em cotas mais altas, formando um microrrelevo na zona aparentemente plana. Nas zonas mais elevadas dos microrrelevos, pode-se ter perfis plínticos.

Estimadas as unidades geotécnicas, com as siglas $\mathrm{ABCxyz}$, é necessário um intenso trabalho de campo. O critério inicial é definir, como na pedologia, o grau de desenvolvimento do horizonte B. Neste item, é feita uma classificação baseada na Classificação Brasileira, mas com menos detalhes e adaptada para a engenharia de solos. Estudos pedológicos mais rigorosos podem ser feitos por pedólogos. A classifi- cação simplificada sugerida deve verificar as seguintes características no perfil.

- Horizonte A - Espessura do horizonte A. Existência de gradiente textural entre os horizontes A e B.

- Horizonte B - O grau de desenvolvimento do horizonte B. Este é analisado através da cor, espessura, presença de minerais primários intemperizáveis, textura, estrutura e drenagem. O horizonte B é classificado como B latossólico, B textural, B pouco desenvolvido e sem horizonte B.

Os solos com B latossólico são facilmente identificados no campo. Dúvidas podem ocorrer com a Terra Roxa-Estruturada e com alguns solos do tipo Podzólico Vermelho-Amarelado e Podzólico Vermelho-Escuro. Quando estes tiverem horizontes B laterítico, num primeiro grupo podem constar numa mesma associação do ponto de vista pedológico. Através do gradiente textural, do grau de desenvolvimento do horizonte B e da estimativa das unidades geotécnicas realizadas no estudo de escritório, é possível checar as unidades com as previstas no estudo preliminar. Muitas vezes, diferentes unidades pedológicas podem resultar em similares unidades geotécnicas. Como exemplo, podemos citar alguns Cambissolos e Litólicos, ambos com o mesmo substrato, que podem resultar em semelhantes perfis geotécnicos.

Verificar se, no horizonte $\mathrm{B}$, ocorrem camadas mais porosas e/ou existência de camadas mais endurecidas. Verificar a ocorrência de camadas onde estão presentes locais com processo de redução do ferro. Por exemplo, solos vermelhos homogêneos com mosqueados cinzentos e amarelos. Examinar a espessura e características das zonas de transição entre o horizonte B e C.

Os solos hidromórficos são separados inicialmente pela topografia. Posteriormente, seguindo o trabalho de CAMARGO et al. (1987), são analisados os graus de desenvolvimento do horizonte B e o gradiente textural.

- Horizonte C - Através da geologia, estimar as características do horizonte C. Verificar se este é formado por solo que guarda a estrutura do material de origem. Verificar o grau de desenvolvimento do horizonte $\mathrm{C}$. Tentar formar - no campo, através de torrões, mesmo não pertencentes ao mesmo perfil, mas com ocorrência na escavação - um perfil de intemperismo. Procurar material-matriz intacto e parcialmente intemperizado. Descrever as características dos principais minerais primários existentes, como quartzo, mica moscovita ou outros que podem ser facilmente reconhecidos no campo. Estimar as porcentagens de ocorrência. Descrever a textura. Verificar as condições de drenagem do 
horizonte $\mathrm{C}$ e a possível ocorrência do lençol freático. Analisar as ocorrências de fraturas, fissuras, xistosidade, estratificação, diaclases ou outras características estruturais do material de origem que favorecem o processo de intemperismo. Verificar se as inclinações da superfície de fraqueza provocam o escorregamento. Observar a presença de matacões e o grau de desenvolvimento dos solos que se situam próximo aos matacões. Verificar se o intemperismo é esferoidal. Descrever características de erosão dos horizontes e instabilidade dos taludes naturais. Verificar se não há presença de camadas de solos ou se este ocorre somente em fraturas ou fissuras. Verificar as inclinações dos cortes existentes na região estudada e sua possível estabilidade.

\section{CONCLUSÕES}

A partir do mapeamento geotécnico proposto, o qual está sendo usado no Sul do Brasil, é possível estimar características geotécnicas necessárias para o uso e ocupação do solo. Baseado neste mapeamento e determinação de características, são definidas cartas temáticas para as várias aplicações, como cartas de áreas de risco, de erosão com indicativo dos horizontes erosivos, de jazidas de solos para pavimentação usando material local, habitações de baixo custo, cerâmica e solo estabilizado e ainda jazidas de solos que quando compactados são impermeáveis. É possível definir áreas para colocação de rejeitos, cartas de fundação e outras importantes para a expansão urbana. $\mathrm{O}$ conhecimento do comportamento dos solos, fundamentado em duas ciências bastante posicionadas, está mostrando bons resultados. Neste sentido, uma metodologia envolvendo conhecimentos pedológicos, geológicos, topográficos e experiência de campo com avaliação laboratorial do comportamento dos solos está sendo desenvolvida com êxito nas pesquisas de comportamento e mapeamento dos solos do Estado do Rio Grande do Sul. Em zonas urbanas ou outros locais em que não existem levantamentos pedológico ou geológico específicos para a região estudada, recomendam-se a utilização de levantamentos regionais e um estudo simplificado de pedologia e geologia baseada em trabalhos de campo.

\section{AGRADECIMENTO}

A autora agradece aos alunos do mestrado, bolsistas de aperfeiçoamento, de ininiação científica, aos professores Egon Klamt e Jarbas Milititsky que pelos seus esforços e suas sugestões proporcionaram a execução desta metodologia e à Fapergs, CNPq e Finep pelo apoio financeiro para a execução deste trabalho.

\section{REFERÊNCIAS BIBLIOGRÁFICAS}

BASTOS, C.A.B. 1991. Caracterização geotécnica dos solos oriundos de rochas graníticas do Município de Porto Alegre. Dissertação de Mestrado, CPGEC/ UFRGS. Porto Alegre.

CAMARGO, M.; KLAMT, E. \& KAUFFMAN, J.H. 1987. Classificação dos solos usados em levantamentos pedológicos no Brasil. Bol. Inf. Soc. Bras. Ciência dos Solos. Campinas, 12(1):11-33.

DIAS, R. 1987. Aplicação de pedologia e geotecnia no projeto de fundações de linhas de transmissão. Tese de Doutorado, COPPE/UFRJ, Rio de Janeiro.

DIAS, R. D. 1988. Estudos de reconhecimento pedológico dos solos do Brasil Leste. Relatório CNPq, Porto Alegre.

DIAS, R. G. 1988. Solos lateríticos do Rio Grande do Sul. Ocorrência e caracterização geotécnica. Solos e Rochas. 10 (2), agosto.

DIAS, R. D.; BASTOS, C.A.B. \& PINHEIRO, R.J.B. 1993. Carta geotécnica bási- ca da grande Porto Alegre visando ao uso e ocupação urbanas. In: FORUM NACIONAL SOBRE GEOLOGIA DOS MEIOS URBANOS, $1^{\circ}$, p. 134142, Porto Alegre..

DIAS, R. D.; BASTOS, C.A.B. \& PINHEIRO, R.J.B. 1994. Perfis de solos residuais da região metropolitana de Porto Alegre. Revista Solos e rochas. Publicação especial comemorativa do aniversário da COPPE/UFRG.

DIAS, R. D. \& MILITITSKY, J. 1990. Proposta de um Sistema de Classificação de Unidades Geotécnicas e Definição de Perfis Compostos de Solos Tropicais e Subtropicais. Publicação Interna. CPGEC/UFRGS. Porto Alegre.

GONZALEZ, M. C. D. 1981. Caracterização e comportamento de um solo argilo típico da região de Manaus, CPGEC/UFRGS.

LEMOS, R. C. \& SANTOS, R. D. 1982 Manual de desçrição e coleta de solos no campo.: Sociedade Brasileira de Ciência dos Solos. Campinas. 
MAGALHÃES, J.A.C. 1990. Escorregamento de base de um talude de solo residual de granulito de Salvador. Dissertação de Mestrado, CPGEC/UFRGS.

ORLANDINI, R. 1991. Estudo do comportamento geomecânico de perfis típicos de solos do Município de Novo Hamburgo visando ao mapeamento geotécnico. Dissertação de Mestrado, CPCGEC
/UFRGS. Porto Alegre.

PINHEIRO, R.J.B. 1991. Estudo do comportamento geomecânico de perfis oriundos de rochas sedimentares da Formação Rosário do Sul. Porto Alegre: CPGEC. Dissertação de Mestrado, CPGEC/UFRGS. 148p.

SANTOS, G.T. 1990. Caracterização geotécnica de riodacitos de Santa Catarina. Dissertação de Mestrado, CPGEC /UFRGS. 